\title{
Exílio: aproximações entre uma educação popular e clandestina
}

\author{
Ângela Cristine Schulz \\ Lucas Romeira de Oliveira ${ }^{2}$ \\ Éder da Silva Silveira ${ }^{3}$ \\ Cheron Zanini Moretti ${ }^{4}$
}

\section{RESUMO}

O presente artigo resulta do trabalho cooperativo entre os projetos Educação Clandestina e Traição: uma história da educação dos comunistas no Brasil da Guerra Fria e Educação Popular e Pesquisa Ação-Participante: respostas descoloniais no contexto de transmodernidade na América Latina, durante o ano de 2015. Tratamos aqui, das reflexões resultantes da análise das obras escritas pelo educador brasileiro Paulo Freire, durante o tempo em que permaneceu em exílio, no Chile. Sob o prisma desta experiência, expressa em Educação como prática da Liberdade e Pedagogia do Oprimido, buscamos compreender como ocorreu a aproximação de educação popular e clandestina vivenciada no movimento de alfabetização que ficou conhecido como os Círculos de Cultura, planejados e executados por Freire e outros educadores, em várias regiões do Brasil, entre meados dos anos de 1950 e início da década de 1960.

Palavras-Chave: Exílio. Educação Popular. Educação Clandestina. Paulo Freire.

\begin{abstract}
This present article results from the cooperative work between the projects Clandestine Education and Betrayal: an education history of the communists in Cold War Brazil and Popular Education and Participant Action Research: decolonials answers in transmodernity context in Latin America, during the year 2015. We are going to present the resulting reflections of the analysis of the written works by Brazilian educator Paulo Freire during his exile in Chile. Under the light of his experience expressed in Education as the Freedom Practice and the Oppressed Pedagogy, we look for an understanding on how this approach between popular and clandestine Education experience in literacy happens, activity that became known as Culture Circles, designed and executed by Freire and other educators, in many regions in Brazil between 1950 years and the beginning of the decade of 1960 .
\end{abstract}

Keywords: Exile. Popular Education. Clandestine Education. Paulo Freire.

\footnotetext{
${ }^{1}$ Aluna do Curso de Pedagogia da Universidade de Santa Cruz do Sul - UNISC.

${ }^{2}$ Aluno do Curso de História da Universidade de Santa Cruz do Sul.

${ }^{3}$ Professor do Departamento de História e do Programa de Pós-Graduação em Educação na Universidade de Santa Cruz do Sul.

${ }^{4}$ Professora do Departamento de Educação e do Programa de Pós-Graduação em Educação na Universidade de Santa Cruz do Sul.<cheron@unisc.br>
} 


\section{INTRODUÇÃO}

O presente artigo resulta do trabalho de intersecção entre os projetos de pesquisa Educação Clandestina e Traição: uma história da educação dos comunistas no Brasil da Guerra Fria e Educação Popular e Pesquisa Ação-Participante: respostas descoloniais no contexto de transmodernidade na América Latina ${ }^{5}$, realizado durante o ano de 2015. Para tanto, foram estudadas as principais obras escritas por Paulo Freire, na década de 1960, no Chile: Educação como prática da Liberdade (1989) e Pedagogia do Oprimido (1974).

O principal objetivo do estudo realizado foi o de, a partir da experiência de exílio (REXHEPI, 2010) de Paulo Freire, compreender como se dá a aproximação da educação popular com a produzida na clandestinidade. E, assim, analisar as experiências dos Círculos de Cultura, criados por Freire, enquanto cultura coletiva e rede de educação clandestina, aquelas que antecederam o Golpe de 1964 e os que permaneceram em atividade, mesmo com o período de fechamento da democracia.

Não podemos deixar de apontar, segundo os aspectos citados anteriormente, a relevância desse estudo no que tange à construção de uma História da Educação desenvolvida em espaços não escolarizados, sua contribuição para a compreensão sobre a educação produzida no clandestino e, principalmente, a importância da experiência do exílio para Paulo Freire na reinvenção de seu próprio método.

A metodologia utilizada se sustenta na análise bibliográfica das obras citadas anteriormente. Destacamos aqui que a primeira fonte analisada (Educação como prática da Liberdade) preocupa-se em discutir uma educação para uma sociedade em trânsito e estabelece a importância desse mesmo movimento sobre as consciências dos sujeitos. Já o segundo livro (Pedagogia do Oprimido), apresenta a necessária superação da contradição opressor-oprimido e tem como base uma educação que se realiza através da relação dialética entre prática-teoria-prática e do diálogo, uma educação capaz de formar cidadãos políticos, conscientes e libertos, transformadores de/com seu próprio mundo.

Como uma melhor forma de organizar nossas investigações, o leitor e a leitora encontrarão o texto subdividido da seguinte maneira: em os "Círculos de Cultura no exílio e na clandestinidade", procuramos historiar esse movimento educacional, tão caro para as pedagogias alternativas e contra hegemônicas, também visando problematizar os efeitos do

\footnotetext{
${ }^{5}$ Ambos projetos estão vinculado ao Programa de Pós-Graduação em Educação, da Universidade de Santa Cruz do Sul, sendo coordenados, respectivamente, pelo Prof. Dr. Éder da Silva Silveira e pela Prof. ${ }^{a}$ Dra. Cheron Zanini Moretti.
} 
exílio nas experiências vivenciadas por Paulo Freire, quando na condição de exilado, no Chile. Já em "As aproximações entre educação popular e clandestina”, apresentamos ambos os livros que são objetos de nossas análise, assim como as reflexões pertinentes aos objetivos desta pesquisa. Para isso, elegemos quatro categorias, sendo elas "educação e clandestinidade", “educação e política”, "educação e conscientização" e "educação e libertação". Por fim, apresentamos nossos resultados parciais, onde buscamos não limitar este trabalho como algo pronto e finito, mas sim como o fio condutor para outras reflexões possíveis.

\section{OS CÍrCULOS DE CULTURA NO EXÍlio E NA CLANDESTINIDADE: FUNDAMENTAÇÃO TEÓRICA}

Os Círculos de Cultura, símbolo mais adequado à lembrança das experiências de cultura e de educação popular realizados no Brasil e na América Latina, foram iniciados por Paulo Freire no final dos anos 1950 e início dos anos 1960 na região nordeste do Brasil (BRANDÃO, 2008). Estes foram realizados em várias outras partes do país e caracterizavamse por experiências de trabalhos com grupos. Estes grupos eram compostos por trabalhadores e populares que se reuniam sob a coordenação de um educador ou educadora. O principal objetivo não era o de "transmitir conteúdos específicos", ao contrário, era partir da realidade do educando e da educanda para discutir temas sobre suas vivências e experiências cotidianas para ler a palavra e ler o mundo.

Portanto, visavam uma educação centrada no sujeito, na construção de seu próprio conhecimento através da tomada de consciência e da ação. Tratava-se de uma educação que leva em consideração o contexto social e histórico. Logo, esta possui um fundamento básico: "ninguém educa ninguém, ninguém educa a si mesmo, os homens se educam entre si, mediatizados pelo mundo" (FREIRE, 2014, p.95); ou seja, o sujeito é capaz de alfabetizar-se e educar-se, aprendendo a ler através do mundo através deste.

Tomando o exposto acima, podemos aproximar a educação popular e a clandestina dos círculos de cultura criados por Freire, pois estes visavam a inserção do homem no processo de mudança, de transformação da sociedade brasileira. Na década de 1960, com o Golpe Civil Militar e a instauração da ditadura, há o fechamento destes círculos e, segundo Balduíno Andreola, Gomercindo Ghiggi e Evaldo Pauly (2011), eles continuaram a existir de forma clandestina e silenciosa no Brasil e no Chile. Também é interessante considerar que, de acordo com esses autores: 
Depois do golpe de estado vários educadores populares importavam clandestinamente, do Uruguai, o livro "Pedagogia do Oprimido", editado lá em 1970, sendo que no Brasil só o foi em 74, assim mesmo com o Prefácio do Fiori misteriosamente censurado, com a eliminação de uma página inteira que, segundo ele próprio, continha o núcleo central de seu pensamento. Entre os que trouxeram do Uruguai "Pedagogia do Oprimido", cabe lembrar o saudoso Padre Cláudio Neutzling, que foi o animador principal de um projeto amplo de alfabetização e educação popular na periferia de Pelotas. O Professor Roberto Zwetsch, docente da Escola Superior de Teologia de São Leopoldo, refere que um grupo de estudantes daquela instituição, ligados a atividades de educação popular, conseguia o livro Pedagogia do Oprimido do Uruguai através da Livraria Selbach, daquela cidade. (ANDREOLA, GHIGGI e PAULY, 2011, p 10)

Segundo Paulo Freire, quando você toma distância do Brasil, do seu país de origem, você se vê e se revê no próprio contexto em que você revê. Assim, você reaprende e compreende como aprendeu e, principalmente, como atuou como educador. Para ele, o exílio possuiu um aspecto extremamente pedagógico, conforme escreve em uma correspondência a Frei Beto: "[...] quando, exilado, tomei distância do Brasil, comecei a compreender-me e a compreendê-lo melhor. Foi exatamente ficando longe dele, preocupado com ele, que me perguntei sobre ele.” (FREIRE apud GADOTTI, 1996, p.162).

Nesta mesma circunstância, Freire procurou evitar a transformação da saudade válida em nostalgia - algo recorrente, quando nos encontramos distantes do nosso país de origem, convertendo-a em aprendizado sobre o novo contexto em que estava inserido: com o mundo. Em seus escritos, relata que não andou no mundo como turista, peregrino ou viajante e sim como educador, examinando, ouvindo e aprendendo com outros educadores locais. Assim, compreendemos por exílio como sendo a "distância crítica de qualquer e de todas as identidades culturais (...) posição reflexiva e híbrida (...) a partir do qual se podem observar e analisar as implicações e os padrões da opressão (...) um meio de resistência produtivo e realista". (REXHEPI, 2010, p.170). A educação (popular) libertadora proposta por Paulo Freire, portanto, mais do que preocupações localizadas em espaços e/ou tempos tem a ver com a vida das gentes, ou seja, a educação é posicionamento crítico e ético. Nesse sentido, a sua experiência de e no exílio ultrapassam os limites de oposição à ideia de pátria (lugar) e se (re)cria como práxis crítica que leva para a vocação ontológica de ser mais humano. (REXHEPI, 2010; FREIRE, 2014).

De acordo com o exercício crítico de análise das obras supracitadas, foi possível depreender que os Círculos de Cultura correspondiam a uma síntese dessa educação popular que, contingenciada pelas circunstâncias da clandestinidade, objetivava tanto uma alfabetização conscientizadora para a responsabilidade social e política como a organização 
do povo para a luta por direitos e justiça. A educação popular não surge com Paulo Freire não ${ }^{6}$. Porém, foi através dele que a educação feita com o povo, com os oprimidos ou as classes populares explicitou sua orientação para a transformação da sociedade partindo do "contexto concreto/vivido para se chegar ao contexto teórico, o que requer curiosidade epistemológica, a problematização, a rigorosidade, a criatividade, o diálogo, a vivência da práxis e o protagonismo do sujeito" (PALUDO, 2010, p.141).

\section{APROXIMAÇÕES ENTRE EDUCAÇÃO POPULAR E CLANDESTINA}

A obra Educação como prática de Liberdade, que teve sua primeira edição no ano de 1967, Freire apresenta o método de alfabetização de adultos - que posteriormente seria chamado de Método Paulo Freire - de forma esmiuçada, contextualizando historicamente a sua proposta e expondo seus pressupostos filosóficos e políticos.

É preciso destacar aqui, a introdução escrita por Francisco Weffort, que narra a experiência resultante da experiência do método proposto Freire na cidade de Angicos, no Rio Grande do Norte, em 1962, onde 300 trabalhadores rurais foram alfabetizados em 45 dias. Entre junho de 1963 e março de 1964, desenvolveram-se cursos de capacitação de coordenadores em várias capitais dos estados brasileiros. No início de 1964, estava prevista a instalação de 20.000 círculos de cultura para dois milhões de analfabetos. O golpe civilmilitar interrompeu os trabalhos e reprimiu toda a mobilização popular já conquistada. Paulo Freire ficou detido por 70 dias e depois foi exilado.

Já em Pedagogia do Oprimido - originalmente publicado em 1974 no Brasil, Freire expõe a questão da relação de contradição (dialética) entre opressores versus oprimidos e de como é necessária uma práxis que pudesse orientar uma ação educativa visando a superação dessas contradições, através de um processo de liberdade.

Assim, a libertação do estado de opressão é uma ação social, não podendo, portanto, acontecer isoladamente. O ser humano é um ser social e, por isso, a consciência e transformação do meio devem acontecer em sociedade. No entanto, podemos nos perguntar: como poderá o indivíduo/sujeito libertar-se da opressão se os que lhe "ensinam" são, por sua vez, também aqueles que os oprimem?

\footnotetext{
${ }^{6}$ Sobre esse tema, especificamente, recomendamos a consulta a: STRECK, Danilo R.; ADAMS, Telmo; MORETTI, Cheron Z. Pensamento pedagógico em nossa América: uma introdução. In: STRECK, Danilo R. (Org). Fontes da Pedagogia Latino-americana: Uma antologia. Belo Horizonte: Autêntica Editora, 2010, pp.1936.
} 
No desenvolver desse livro, Paulo Freire procura alertar o professor - enquanto mediador do conhecimento - sobre seu papel problematizador da realidade do educando e de como a educação também tem um papel importante nesse processo de busca pela liberdade. Desta forma, através da leitura das duas obras selecionadas e da experiência de Freire no exílio, e a compreensão que atribui a essa experiência, pudemos apontar as seguintes reflexões sobre: a) educação popular e clandestinidade; b) educação e política; c) educação e conscientização; d) educação e liberdade.

\section{a) Educação Popular e Clandestinidade}

A educação popular muitas vezes é confundida com a educação pública. Não raro, atribui-se a esta um sentido de "popular" como sinônimo de uma "educação para o pobre" ou uma "educação de menor valor". (STRECK et. al., 2010). Contudo, a educação popular possui uma relação com os movimentos sociais, com movimentos e ações contra práticas culturais e educativas dominantes, opressoras. Os Círculos de Cultura, portanto, destinavam-se a esta educação popular, uma educação direcionada e construída para atender a população excluída do processo educativo, uma educação feita a partir do conhecimento do povo e com o povo.

É no contexto de negação de ser mais que a educação popular se insurge, sobretudo nos anos em que se viveu um sistema fechado, tanto no Brasil quanto em boa parte da América Latina. Devido ao contexto político iniciado nos anos de 1960, sobretudo, é que os círculos de cultura, em muitos momentos, tiveram que educar-se, fazer-se de um modo clandestino.

A Clandestinidade, para tanto, deve ser entendida como um conceito polissêmico e complexo, uma vez que seria um ato arbitrário vinculá-la a um único significado. São poucos os trabalhos que se dedicam a analisar a clandestinidade, tornando a acepção desta condição um processo deveras cauteloso, já que a tendência a reduzir o clandestino ao ilegal, ou mesmo com o exílio, se mostra presente no entendimento comum da palavra e não como a tomamos a partir de Freire.

Andreola, Ghiggi e Pauly, quando analisam o movimento de educação popular empreendido pelos Círculos de Cultura no RS, nos lembram que:

O Instituto de Cultura Popular não deixou de ter, porém, desdobramentos e influências que perduram até hoje. Mesmo durante a ditadura, continuaram aqui, no Rio Grande do Sul, de forma silenciosa, e no Chile, através de Freire, de Fiori e de outros exilados, importantes atividades inspiradas em Freire. (2011, p. 10) 
Nesse sentido, os Círculos de Cultura, além de se constituírem como espaços onde prevalecia uma educação popular alicerçada sobre o método desenvolvido por Freire, e que também passaram a funcionar de forma clandestina durante o período do Regime Militar, também consistiam em espaços de resistência, tanto dos educandos quanto dos mediadores do conhecimento.

\section{b) Educação e Política}

Os Círculos de Cultura não consistiam somente nos atos de ler e de escrever, mas sim de formar o sujeito em um ser pensante, autônomo, crítico, criativo e consciente a partir da realidade, do contexto em que se estava inserido. Segundo Weffort (apud Freire, 1989), os sujeitos que faziam parte dos Círculos de Cultura tornavam-se cidadãos politicamente ativos, disponíveis a uma participação democrática e este fato acabou por assustar a elite brasileira que foi a primeira a perceber esta mudança.

Neste período o Brasil vivia um momento de transição, com uma sociedade ainda muito fechada e assistencialista. Paulo Freire nos propõe que ocorresse uma transitividade coletiva: de um sistema fechado para um sistema aberto. A educação era muito autoritária e centrada nas mãos do Estado, portanto, haveria de existir uma educação feita para o povo e com este, onde se tivesse condições de superar o analfabetismo e a sua situação desumanizante. Uma educação comprometida com a realidade, mediante a capacidade de reflexão:

\footnotetext{
Tínhamos de nos convencer desta obviedade: uma sociedade que vinha e vem sofrendo alterações tão profundas e às vezes até bruscas e em que as transformações tendiam a ativar cada vez mais o povo em emersão, necessitava de uma reforma urgente e total no seu processo educativo. Reforma que atingisse a própria organização e o trabalho educacional em outras instituições ultrapassando os limites mesmos das estritamente pedagógicas. Necessitávamos de uma educação para a decisão, para a responsabilidade social e política. (FREIRE, 1989, p.88)
}

Aquele sistema educacional carecia de professores e professoras mais democráticos(as), pois nele ainda estava muito enraizada a concepção bancária de educação, uma educação como instrumento de opressão. Nesta, não havia uma comunicação interativa entre educador e educando e a relação entre estes era através de simples comunicados, “transmissões" de conteúdo, tornando os discentes meros depósitos a serem preenchidos. 
Consequentemente, entendia-se que o professor era o detentor exclusivo do conhecimento, o único que tinha poder de educar, aquele que transmitia o conhecimento e os conteúdos. Os alunos eram considerados ignorantes, aqueles que nada sabiam, uma "tábula rasa", que somente recebem e absorvem este conhecimento, permanecendo em sua posição passiva de ser.

Contudo, em frente a esta educação havia de ocorrer uma mudança, uma reforma urgente neste processo educativo. Uma educação centrada no aluno, onde ocorresse uma troca de experiências entre o mundo, educador e educando através da dialogicidade. Para tanto, esta educação problematizadora e dialogante teve que ocorrer de forma clandestina.

\section{c) Educação e Conscientização}

A conscientização é um dos conceitos básicos da educação popular. Por isso, havia necessidade de alfabetizar essa imensa massa de oprimidos, para que ela pudesse ter conhecimento e capacidade de agir conscientemente sobre a sua realidade na construção de seu próprio mundo. Assim, nesta mesma proporção:

Desde logo, afastáramos qualquer hipótese de uma educação puramente mecânica. Desde logo, pensávamos a alfabetização do homem (sic) brasileiro, em posição de tomada de consciência, na emersão que fizera no processo de nossa realidade. Num trabalho com que tentássemos a promoção da ingenuidade em criticidade, ao mesmo tempo que alfabetizássemos. (FREIRE, 1989, p. 104)

Inicialmente, o sujeito possui uma posição ingênua diante de sua realidade objetiva e aos fatos recorrentes em seu contexto de opressão. No momento em que este adota uma posição crítica diante desta realidade, tomando uma decisão através da "justa raiva", o sujeito transforma sua consciência de ingênua para crítica. Logo, através da promoção desta transitividade das consciências, desenvolvendo sua criticidade, alcançando a conscientização.

É através desta expectativa de apreender e analisar a realidade em que ele se apresenta que este sujeito começa a se dar conta de seu papel no mundo e com o mundo. Segundo Freire, (1989, p. 109), “o homem (sic), afinal, no mundo e com o mundo. O seu papel de sujeito e não de mero permanente objeto". Assim, quanto mais conscientes e cientes de seu papel como sujeitos, mais se aproximariam da realidade em que para eles se apresentava. 
Compreende-se, com isso, que a conscientização se dá por meio da "práxis", ou seja, a partir da íntima ligação entre a ação e a reflexão. É através desta relação entre a prática e o pensamento que o sujeito seria capacidade de atuar e transformar sua realidade social, transformando-se em ser ontológico, na sua busca de ser mais. É, portanto, pela tomada de consciência, relacionada a "práxis", que o sujeito consegue se estruturar assumindo e construindo seu compromisso histórico e, assim, fazendo - se sujeito histórico.

\section{d) Educação e Libertação}

Quando os sujeitos/indivíduos se politizam e se conscientizam, começam a se libertar. E, para que ocorra esta libertação, é necessário haver uma mudança radical na mentalidade dos oprimidos. Esta libertação da opressão não deve ocorrer "para" os oprimidos e sim através destes, com estes, por meio de um processo de conscientização, na luta organizada para a superação deste regime dominador/autoritário. Assim, segundo Freire (2014, p.71):

\footnotetext{
Ninguém liberta ninguém, ninguém se liberta sozinho: os homens se libertam em comunhão [...] Somente quando os oprimidos descobrem, nitidamente, o opressor, e se engajam na luta organizada por sua libertação, começam a crer em si mesmos [...] os oprimidos, nos vários momentos de sua libertação, precisam reconhecer-se como homens, na sua vocação ontológica e histórica de ser mais.
}

De acordo com Freire, esta pedagogia libertadora possui dois momentos distintos: num primeiro momento, os oprimidos vão se desprendendo do mundo da opressão a partir da sua transformação através da práxis e, num segundo momento, ao modificar esta realidade atual, esta pedagogia deixa de ser do oprimido e passa a ser dos homens em processo de libertação.

Neste âmbito, os indivíduos precisam fazer uma leitura crítica do mundo, através da reflexão e ação, reconhecendo-se como homens e mulheres no mundo e com um mundo. Com isso, como seres humanos inacabados, incompletos e inconclusos, cientes desta inconclusão, são capazes de transformarem-se transitivamente de consciência, por meio do seu contexto histórico, do meio em que vivem, construindo sua própria libertação. Segundo Weffort (apud Freire, 1989, p. 9), “a ideia da liberdade só adquire plena significação quando comunga com a luta concreta dos homens por libertar-se".

Em razão do que foi explanado anteriormente, a base, a essência desta educação como prática da liberdade é o diálogo. Este se constitui da palavra e possui duas perspectivas 
fundamentais: a ação e a reflexão. O diálogo seria o melhor meio de fixar relações e estabelecer uma relação horizontal, ou seja, uma relação de confiança entre os sujeitos. Contudo, a palavra não pode ser privilégio de alguns, e sim, direito de todos.

\begin{abstract}
Sendo fundamento do diálogo, o amor é, também, diálogo. Daí que seja essencialmente tarefa de sujeitos e que não possa verificar-se na relação dominação. Nesta, o que há é patologia de amor: sadismo quem domina; masoquismo nos dominados. Amor, não. Porque é um ato de coragem, nunca de medo, o amor é compromisso com os homens. Onde quer que estejam estes, oprimidos, o ato de amor está em comprometer-se com sua causa. A causa de sua libertação. Mas, este compromisso, porque é amoroso, é dialógico (FREIRE, 2014, p. 110).
\end{abstract}

Logo, educar por meio do diálogo, através desta luta pela liberdade, representa um ato de comprometimento e de amor, pois só através deste contexto, deste compromisso com o outro, podemos vencer o medo, abrir horizontes e introduzir a esperança.

\title{
ALGUMAS CONSIDERAÇÕES
}

Podemos compreender, através do estudo da Educação como prática da Liberdade e Pedagogia do Oprimido - obras produzidas por Paulo Freire enquanto exilado, suas contribuições para repensarmos a educação que considere a realidade do sujeito ao mesmo tempo que possa mediar sua emancipação e empoderamento.

Desta forma, o ser humano, como agente histórico (no mundo e com o mundo), deve ser capaz de estabelecer esta relação, recriando-o por meio de uma prática reflexiva, no compromisso da busca pela justiça e transformação de seu contexto, através do despertar da tomada da consciência, desalienação e politização do homem e da mulher.

Para que a educação popular funcione como uma prática da liberdade, a dialogicidade deve sempre ter primazia, pois a palavra e a educação não deve ser privilégio de uma determinada classe social, mas um direito de todos.

Também podemos enfatizar que os livros escritos durante a experiência de Paulo Freire no exílio nos remetem a uma ampla significação, ou seja, a polissemia da palavra clandestinidade. Com isso, é importante ressaltar que Freire não vive a clandestinidade, mas suas obras e seu método é que foram colocados no clandestino. É neste contexto, por ainda estar vivendo num sistema muito fechado, que as experiências de educação popular (círculos de cultura) tiveram que ocorrer, muitas vezes, "no proibido", no clandestino, ou até mesmo de forma invisível, como mencionado anteriormente. 


\section{REFERÊNCIAS}

ANDREOLA, B. A.; GHIGGI, G.; PAULY, E. L. Paulo Freire no Rio Grande do Sul diálogos, aprendizagens e reinvenções. Revista E-Curriculum. São Paulo, n.2, v. 7, p.1-20, 2011.

BRANDÃO, C. R. Círculo de Cultura. In: STRECK, D.; REDIN, E.; ZITKOSKI, J. J. (Org.). Dicionário Paulo Freire. Belo Horizonte: Autêntica, 2008.

FREIRE, P. Educação como Prática da Liberdade. 19. ed. Rio de Janeiro: Paz e Terra, 1989.

FREIRE, P. Pedagogia do Oprimido. 57. ed. Rio de Janeiro: Paz e Terra, 2014.

GADOTTI, M. Paulo Freire: Uma Biobibliografia. São Paulo: Cortez: Instituto Paulo Freire; Brasília, DF; UNESCO, 1996.

PALUDO, C. Educação Popular. In: STRECK, D.; REDIN, E.; ZITKOSKI, J. J. (Org.). Dicionário Paulo Freire. Belo Horizonte: Autêntica, 2010, pp.139-141.

REXHEPI, J. Exílio. In: STRECK, D.; REDIN, E.; ZITKOSKI, J. J.(Org.). Dicionário Paulo Freire. Belo Horizonte: Autêntica, 2010, p. 170.

STRECK, D. et al. Educação Popular e Docência. 1. ed. São Leopoldo: Cortez, 2010.

STRECK, D. R.; ADAMS, T.; MORETTI, C. Z. Pensamento pedagógico em nossa América: uma introdução. In: STRECK, D. R. (Org). Fontes da Pedagogia Latino-americana: Uma antologia. Belo Horizonte: Autêntica Editora, 2010, p.19-36.

\section{Como citar este documento:}

SCHULZ, Ângela Cristine et al. Exílio: aproximações entre uma educação popular e clandestina. Revista Jovens Pesquisadores, Santa Cruz do Sul, v. 6, n. 2, nov. 2016. ISSN 2237-048X. Disponível em: 〈https://online.unisc.br/seer/index.php/jovenspesquisadores/article/view/7304〉. Acesso em: ... doi:http://dx.doi.org/10.17058/rjp.v6i2.7304. 